\title{
The long-term impact of the Food Dudes Healthy Eating Programme on Irish primary school aged children
}

\author{
C. Martin, M. Concannon, S. Bel-Serrat, M. Heinen and C.M. Murrin \\ UCD School of Public Health, Physiotherapy and Population Science, Woodview House, Belfield, Dublin 4, Ireland
}

The Food Dudes Healthy Eating Programme is an evidence based incentivised behaviour changing programme developed by the Food and Activity Research Unit, Bangor University, Wales ${ }^{(1)}$. In Ireland it is managed by Bord Bía, the Irish food board, and was first rolled out in 2005. The programme's aim is to increase sustained fruit and vegetable consumption amongst primary school children through the provision and repeated tasting of fruit and vegetables in school. The aim of the present study is to identify if the programme can sustain increased fruit and vegetables provision and consumption of Irish primary school aged children in the longterm (six years).

The programme was evaluated in 2010-11 using the Food Dudes Quick Eating Diary (FDQED) which had been specifically developed for that evaluation $^{(2)}$, and therefore this tool was used again in 2016 to allow for direct comparison. The FDQED is a teacher administered instrument, which reports a summary measure of class intake of fruit, vegetables and snacks. Data collected from junior and senior infant classes evaluated in 2010-11 following completion of the Food Dudes Healthy Eating Programme, were compared with $5^{\text {th }}$ and $6^{\text {th }}$ class pupils of the same schools 6 years later (2016) using paired samples t-test.

The immediate post-intervention impact seen following delivery of the programme in 2010-11 was not sustained over time. Significant decreases were evident for both fruit and vegetables provision when compared with $2010-11$ (Fruit: $83 \%$ vs. $67 \%$, p = 0.017; Vegetables: $57 \%$ vs. $12 \%, \mathrm{p} \leqslant 0.001$ respectively). Likewise, the proportion of pupils consuming fruit and vegetables was significantly less when compared to 2010-11 (Fruit: $80 \%$ vs. $56 \%, \mathrm{p}=0 \cdot 002$; Vegetables: $53 \%$ vs. $10 \%$, p $\leqslant 0 \cdot 001$ respectively). When compared to the original baseline in 2010-11, prior to having ever received the intervention, the proportions of pupils bringing and consuming fruit (Fruit Brought: $54 \%$ vs. $67 \%, p=0.026$; Fruit Consumed: $47 \%$ vs. $56 \%, p=0.039$ respectively) and vegetables (Vegetables Brought: $6 \%$ vs. $12 \%, p=0.020$; Vegetables Consumed: $4 \%$ vs. $10 \%, p=0.032$ respectively) in school were significantly higher six years following the intervention.

These results suggest that the positive short-term impact of the Food Dudes Healthy Eating Programme is not sustained to the same extent over a six year period, and a significant decrease in impact is seen. However, the present study also indicates that the programme may have some impact on long-term behavioural outcomes when compared to the absence of an intervention.

1. Horne PJ, Hardman CA, Lowe CF et al. (2009) Eur J Clin Nutr 63, 613-618.

2. O'Connor D, McKenzie K \& Wall P (2011) Evaluation of the EU School Fruit Scheme in Ireland. Dublin: Department of Agriculture, Food and the Marine. 